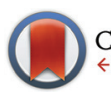

CrossMark

\& click for updates

Cite this: DOI: $10.1039 / \mathrm{c} 5 \mathrm{fo} 00886 \mathrm{~g}$

Received 20th July 2015

Accepted 8th November 2015

DOI: $10.1039 / \mathrm{c} 5 \mathrm{fo} 00886 \mathrm{~g}$

www.rsc.org/foodfunction

\title{
Red wine polyphenols modulate fecal microbiota and reduce markers of the metabolic syndrome in obese patients
}

\author{
Moreno-Indias Isabel, $\uparrow^{\mathrm{a}, \mathrm{b}}$ Sánchez-Alcoholado Lidia, $\dagger^{\mathrm{a}}$ Pérez-Martínez Pablo, ${ }^{\mathrm{b}, \mathrm{c}}$ \\ Andrés-Lacueva Cristina, ${ }^{\text {d,e }}$ Cardona Fernando, ${ }^{\star a, b}$ Tinahones Francisco ${ }^{\star a, b}$ and \\ Queipo-Ortuño María Isabel ${ }^{a, b}$
}

\begin{abstract}
This study evaluated the possible prebiotic effect of a moderate intake of red wine polyphenols on the modulation of the gut microbiota composition and the improvement in the risk factors for the metabolic syndrome in obese patients. Ten metabolic syndrome patients and ten healthy subjects were included in a randomized, crossover, controlled intervention study. After a washout period, the subjects consumed red wine and de-alcoholized red wine over a 30 day period for each. The dominant bacterial composition did not differ significantly between the study groups after the two red wine intake periods. In the metabolic syndrome patients, red wine polyphenols significantly increased the number of fecal bifidobacteria and Lactobacillus (intestinal barrier protectors) and butyrate-producing bacteria (Faecalibacterium prausnitzii and Roseburia) at the expense of less desirable groups of bacteria such as LPS producers (Escherichia coli and Enterobacter cloacae). The changes in gut microbiota in these patients could be responsible for the improvement in the metabolic syndrome markers. Modulation of the gut microbiota by using red wine could be an effective strategy for managing metabolic diseases associated with obesity.
\end{abstract}

\section{Introduction}

The metabolic syndrome (MetS) is a cluster of medical conditions, including obesity and insulin resistance, that increase the risk of developing type 2 diabetes and cardiovascular diseases, which have become an important epidemic worldwide. ${ }^{1}$ Recent studies have demonstrated that obesity and the MetS may be associated with substantial changes in the composition and metabolic function of the gut microbiota. ${ }^{2}$ Several years ago, Vijay-Kumar et al., ${ }^{3}$ using transgenic mice, provided evidence for the direct relationship between the development of the MetS, a malfunction of the innate immune system, and changes in the composition of the gut microbiota.

\footnotetext{
${ }^{a}$ Clinical Management Unit of Endocrinology and Nutrition of the Virgen de la Victoria Hospital, Biomedical Research Institute of Malaga (IBIMA), Malaga, Spain ${ }^{b}$ Biomedical Research Networking Center for Pathophysiology of Obesity and Nutrition, CIBERobn, Madrid, Spain.E-mail:fjtinahones@hotmail.com, fernandocardonadiaz@gmail.com

${ }^{c}$ Lipid and Atherosclerosis Unit, IMIBIC/Reina Sofia University Hospital/University of Cordoba, Spain

${ }^{d}$ Biomarkers and Nutrimetabolomic Lab. Department of Nutrition and Food Science, XaRTA, INSA, Faculty of Pharmacy, University of Barcelona, Barcelona, Spain ${ }^{e}$ INGENIO-CONSOLIDER Program, Fun-c-food CSD2007-06, Barcelona, Spain $\dagger$ These authors contributed equally to this work.
}

The beneficial effects of prebiotic food products on energy homoeostasis, satiety regulation, body weight gain and changes in the composition of the gut microbiota have recently been analyzed in studies using both animal and human models. ${ }^{4}$ Together with data from obese animals and patients, these studies support the hypothesis that the gut microbiota composition (especially the number of bifidobacteria) may contribute to the modulation of metabolic processes associated with the MetS, specifically obesity and type 2 diabetes. $^{5,6}$

Several intervention studies in humans and animals have provided further evidence for the protective effects of polyphenols in the direction of modulation of vascular and platelet function, blood pressure, and an improved plasma lipid profile. $^{7-9}$ Plant polyphenols, which are organic compounds found in numerous plant species and their fruits, are being actively studied as potential treatments for components of the MetS. ${ }^{10-12}$ The use of red wine polyphenols may be a potential mechanism for the prevention of cardiovascular and metabolic alterations associated with obesity. Agouni et al. have provided strong evidence for an improvement in obesity-associated alterations, including glucose and lipid metabolism, as well as endothelial and cardiac functions due to the beneficial effects of red wine polyphenols on both vascular and cardiac functions in a Zucker fatty rat model. ${ }^{13}$ 
The phenolic components in wine also have an effect on the microbiota. Queipo-Ortuño et al. ${ }^{14}$ have recently shown that red wine consumption can significantly modulate the growth of selected gut microbiota in healthy humans. The consumption of red wine polyphenols significantly increased the number of Enterococcus, Prevotella, Bacteroides, Bifidobacterium, Bacteroides uniformis, Eggerthella lenta, and the Blautia coccoidesEubacterium rectale group, while the quantity of Lactobacillus spp. was unaltered. Resveratrol has been identified as being responsible for changes in the intestinal microbiota in rats, with an increase in Bifidobacterium and Lactobacillus levels. ${ }^{15}$ Anthocyanins have in vitro bacteriostatic activity against Staphylococcus spp., Salmonella spp., Helicobacter pylori, and Bacillus cereus, among others. ${ }^{16,17}$ Catechins and epicatechins affect the growth of selected microflora, resulting in an increase in the growth of the Blautia coccoides-Eubacterium rectale group, Bifidobacterium spp. and Escherichia coli, as well as having an inhibitory effect on the Clostridium histolyticum group. ${ }^{18}$

A dietary modulation of the gut microbiota and its metabolic output could positively influence host metabolism and thus constitute a potential coadjuvant approach in the management of obesity and associated metabolic disorders. Thus, our aim was to examine the possible prebiotic effect of a moderate intake of red wine polyphenols on the modulation of the gut microbiota composition and the improvement in the MetS risk factors in obese patients.

\section{Materials and methods}

\section{Study subjects and design}

The study involved 20 Caucasian adult men aged $48 \pm 2$ years (range 45-50 years). Ten obese participants met the criteria for the MetS and 10 were healthy subjects (control group). The MetS patients were recruited if they fulfilled at least three of the updated criteria for the diagnosis of the MetS according to the National Cholesterol Education Program's Adult Treatment Panel III (ATP III): waist circumference > $102 \mathrm{~cm}$; HDL cholesterol < $40 \mathrm{mg} \mathrm{dL^{-1 }}$ in men; serum triglycerides $\geq$ $150 \mathrm{mg} \mathrm{dL}{ }^{-1}$; fasting blood glucose $110-126 \mathrm{mg} \mathrm{dL}^{-1}$ and blood pressure $\geq 130 / 85 \mathrm{mmHg}$.

Exclusion criteria were established for type 2 diabetes: body mass index $(\mathrm{BMI})>40 \mathrm{~kg} \mathrm{~m}^{-2}$; acute or chronic infection, inflammatory disease or endocrine disorders; history of cancer; leukocytosis $\left(>10 \times 10^{9}\right.$ cells per L); anti-inflammatory, corticosteroid, hormone, or antibiotic drug treatment; a history of alcohol abuse or drug dependence; and a restrictive diet or a weight change $\geq 5 \mathrm{~kg}$ during the 3 months prior to the study. None of the 20 volunteers received antibiotic therapy, prebiotics, probiotics, synbiotics, vitamin supplements or any other medical treatment influencing intestinal microbiota during the 3 months before the start of the study or during the study. A randomized, crossover controlled intervention study was performed. The study was divided into 4 periods: an initial washout period of two weeks (baseline) during which the participants did not consume any red wine, followed by two intervention periods of 30 days each during which participants drank only red wine (272 $\mathrm{mL}$ per day) or de-alcoholized red wine ( $272 \mathrm{~mL}$ per day) separated by a washout period of 15 days. Each participant provided 3 different fecal samples: a baseline sample after the washout period and a sample at the end of each 30 day period. Fasting blood samples and $24 \mathrm{~h}$ urine were also collected at baseline and after each intake period. The participants did not smoke or drink other alcoholic beverages and they were only advised to follow the same qualitative dietary recommendations according to the American Heart Association dietary guidelines, ${ }^{19}$ in the absence of any low-in-polyphenols washout diet to mimic their normal free-living conditions as much as possible. Participants were also asked to maintain the same level of physical activity throughout the study. At baseline and after each intervention period, a medical examination and structured nutrient intake and physical activity questionnaires were completed. This information was converted into dietary data using the Professional Diet Balancer software (Cardinal Health Systems Inc., Edina, MN). The Ethics Committee of the Virgen de la Victoria Hospital approved the clinical protocol. All the participants gave written informed consent.

\section{Anthropometric measures}

Body weight, height, waist and hip circumference were measured according to standardized procedures. ${ }^{20}$

\section{Laboratory measurements}

Blood samples were collected after an overnight fast. The serum was separated into aliquots and immediately frozen at $-80{ }^{\circ} \mathrm{C}$. Serum biochemical parameters were measured in duplicate. Serum albumin, glucose, cholesterol, HDL cholesterol, triglycerides (Randox Laboratories Ltd, Antrim, UK), bilirubin (Dimension Vista System, Siemens, Tarrytown, NY), uric acid, C-reactive protein (Dimension autoanalyzer from Dade Behring Inc., Deerfield, IL, USA), gamma-glutamyl transpeptidase, glutamate-oxaloacetate transaminase, and glutamic pyruvic transaminase (Wako Bioproducts, Richmond, VA, USA) were all measured using standard enzymatic methods. Lowdensity lipoprotein cholesterol was calculated using the Friedewald formula. The insulin was analyzed using an immunoradiometric assay (BioSource International, Camarillo, CA, USA), showing a $0.3 \%$ cross-reaction with proinsulin. The intra- and inter-assay CV were $1.9 \%$ and $6.3 \%$, respectively.

Resveratrol and dihydroresveratrol metabolites were analyzed in $24 \mathrm{~h}$ urine samples as biomarkers of red wine intake, by using the technique described by Urpi-Sarda et al. ${ }^{21-23}$ The resveratrol metabolites were quantified by using the commercial and available standards. Dihydroresveratrol was provided by Biopharmalab SL and the concentrations of dihydroresveratrol metabolites were quantified by using a dihydroresveratrol calibration curve. ${ }^{24}$ Similarly, ethyl glucuronide was measured in $24 \mathrm{~h}$ urine samples by liquid chromatography (LC Agilent series 1200 coupled with a hybrid quadrupole time-of-flight QSTAR Elite; Applied Biosystems/MDS Sciex). 


\section{Limulus amebocyte lysate assays}

Serum concentrations of LPS were measured by endotoxin assay, based on a limulus amebocyte extract with a chromogenic limulus amebocyte lysate (LAL) assay (QCL-1000; Lonza Group Ltd). Samples were diluted in pyrogen-free water and heated to $70^{\circ} \mathrm{C}$ for $10 \mathrm{~min}$ to inactivate endotoxin neutralizing agents that inhibit the activity of endotoxin in the LAL assay. The pyrosperse reagent (Lonza Group Ltd), which is a metallomodified polyanionic dispersant, was added at a ratio of $1: 200$ (vol: vol) to test samples before LAL testing to minimize interference in the reaction. All samples were tested in duplicate, and results were accepted when the intra-assay CV was $10 \%$. The endotoxin content was expressed as endotoxin units (EU) per milliliter. Exhaustive care was taken to avoid environmental endotoxin contamination, and all of the material used for both sample preparation and the test was pyrogen-free.

\section{DNA extraction from fecal samples}

Fecal samples were collected and immediately stored at $-80^{\circ} \mathrm{C}$ until analysis. DNA extraction from $200 \mathrm{mg}$ of stools was performed using the QIAamp DNA stool Mini kit (Qiagen, Hilden, Germany) following the manufacturer's instructions. The DNA concentration was determined by absorbance at $260 \mathrm{~nm}$, and the purity was estimated by determining the $A_{260} / A_{280}$ ratio with a Nanodrop spectrophotometer (Nanodrop Technologies, Wilmington, DE, USA).

\section{Analysis of fecal microbiota by polymerase chain reaction- denaturing gradient gel electrophoresis (PCR-DGGE)}

Fecal samples from each subject were examined by determining PCR-DGGE profiles. The V2-V3 region of the 16S rRNA genes (positions 339-539 in the Escherichia coli gene) of bacteria in the fecal samples was amplified with the primers HDA1-GC (5'-CGC CCG CCG CGC GCG GCG GGC GGG GCG GGG GCA CGG GGG GCC TAC GGG AGG CAG CAG T-3' (the GC clamp is in boldface) and HDA2 (5'-GTA TTA CCG CGG CTG CTG GCA C-3'). Aliquots $(2 \mu \mathrm{L})$ of DNA were amplified by RT-PCR ( $20 \mu \mathrm{L}$ final volume) in a 7500 Fast RT-PCR systems instrument using Fast SYBR Green Master Mix and $200 \mathrm{nM}$ of each of the universal primers HDA1-GC/HDA2 with the following amplification program: initial denaturation at $95^{\circ}$ for $20 \mathrm{~s}$, amplification using 45 cycles including denaturation at $95{ }^{\circ} \mathrm{C}$ for $3 \mathrm{~s}$, annealing at $55^{\circ} \mathrm{C}$ for $30 \mathrm{~s}$ and extension at $72^{\circ} \mathrm{C}$ for $1 \mathrm{~min}$.

After RT-PCR, $15 \mu \mathrm{L}$ of products were mixed with a $6 \mu \mathrm{L}$ loading dye before loading. Electrophoresis was performed with a DCode ${ }^{\mathrm{TM}}$ Universal Mutation Detection System instrument (Bio-Rad). 6\% Polyacrylamide gels were prepared and electrophoresed with $1 \times$ TAE buffer prepared from $50 \times$ TAE buffer ( $2 \mathrm{M}$ Tris base, $1 \mathrm{M}$ glacial acetic acid, $50 \mathrm{mM}$ EDTA). The denaturing gradient was formed by using two 6\% acrylamide (acrylamide/bisacrylamide ratio, $37.5: 1$ ) stock solutions (Bio-Rad). The gels contained a $20-80 \%$ gradient of urea and formamide, increasing in the direction of electrophoresis. Electrophoretic runs were performed in a Tris-acetate-EDTA buffer (TAE $1 \times)$ (40 mmol L ${ }^{-1}$ Tris, $20 \mathrm{mmol} \mathrm{L}^{-1}$ acetic acid, and $1 \mathrm{mmol} \mathrm{L}{ }^{-1}$ EDTA, pH 7.4) at $130 \mathrm{~V}$ and $60^{\circ} \mathrm{C}$ for $4.5 \mathrm{~h}$. Electrophoresis was stopped when a xylene cyanol dye marker reached the bottom of the gel. Gels were stained with ethidium bromide $\left(0.5 \mathrm{mg} \mathrm{L}^{-1}\right)$ for $5 \mathrm{~min}$, rinsed with deionized water, viewed by UV transillumination and photographed with Gelcapture image acquisition software (DNR Bio-Imaging Systems Ltd). Similarities between banding patterns in the DGGE profile were calculated based on the presence and absence of bands and expressed as a similarity coefficient (Cs). Gels were analyzed using BioNumerics software (Applied Maths, SintMartens-Latem, Belgium). Normalized banding patterns were used for cluster analysis. The Dice similarity coefficient was used to calculate pairwise comparisons of the DGGE fingerprint profiles obtained. A Cs value of $100 \%$ indicates that DGGE profiles are identical while completely different profiles result in a Cs value of $0 \%$. The UPGMA (unweighted pair group method with arithmetic mean) algorithm was used for the construction of dendrograms.

\section{Sequencing of bands from DGGE gels}

Bands were excised from DGGE gels with a sterile razor, placed in $40 \mu \mathrm{L}$ sterile water and incubated at $4{ }^{\circ} \mathrm{C}$ for diffusion of DNA into the water. DNA was used in a second PCR with HDA1/2 primers without a GC clamp (initial denaturation $95^{\circ}$ for $20 \mathrm{~s}$, followed by 45 cycles including denaturation at $95{ }^{\circ} \mathrm{C}$ for $3 \mathrm{~s}$, annealing at $55{ }^{\circ} \mathrm{C}$ for $15 \mathrm{~s}$ and extension at $72{ }^{\circ} \mathrm{C}$ for $10 \mathrm{~s})$. PCR products were diluted until $20 \mathrm{ng} \mu \mathrm{L}^{-1}$, purified with ExoSAP-IT (USB Corporation, Miles Road, Cleveland, Ohio, USA) and sequenced in an ABI 3130 (Applied Biosystems) using the BigDye-Kit-Standard. Nucleotide sequence data obtained were analyzed using MicroSeqID v2.1.1 software (Applied Biosystems).

\section{Microbial quantification by real-time quantitative PCR}

Specific primers targeting different bacterial genera were used to characterize the fecal microbiota by real-time quantitative PCR (Table 1). ${ }^{25-38}$ Briefly, real-time quantitative PCR experiments were performed with a LightCycler 2.0 PCR sequence detection system using the FastStart DNA Master SYBR Green kit (Roche Diagnostics, Indianapolis, IN, USA). All PCR tests were carried out in duplicate with a final volume of $20 \mu \mathrm{L}$, containing $1 \mu \mathrm{L}$ of each fecal DNA preparation and $200 \mathrm{nM}$ of each primer (Table 1). The thermal cycling conditions used were as follows: an initial DNA denaturation step at $95{ }^{\circ} \mathrm{C}$ for $10 \mathrm{~min}$, followed by 45 cycles of denaturation at $95^{\circ} \mathrm{C}$ for $10 \mathrm{~s}$, primer annealing at the optimal temperature (Table 1) for $20 \mathrm{~s}$, and extension at $72{ }^{\circ} \mathrm{C}$ for $15 \mathrm{~s}$. Finally, melt curve analysis was performed by slowly cooling the PCRs from 95 to $60{ }^{\circ} \mathrm{C}$ (0.05 ${ }^{\circ} \mathrm{C}$ per cycle) with simultaneous measurement of the SYBR Green I signal intensity. Melting-point-determination analysis allowed the confirmation of the specificity of the amplification products.

The bacterial concentration from each sample was calculated by comparing the Ct values obtained from the standard curves with the LightCycler 4.0 software. Standard curves were 
Table 1 Primers used for real-time PCR

\begin{tabular}{|c|c|c|}
\hline Target group & Oligonucleotide sequence $\left(5^{\prime}-3^{\prime}\right)$ & Reference \\
\hline Bacteroidetes & $\begin{array}{l}\text { CATGTGGTTTAATTCGATGAT } \\
\text { AGCTGACGACAACCATGCAG }\end{array}$ & Guo et al., $2008^{25}$ \\
\hline Bacteroides & $\begin{array}{l}\text { GAGAGGAAGGTCCCCCAC } \\
\text { CGCTACTTGGCTGGTTCAG }\end{array}$ & Guo et al., $2008^{25}$ \\
\hline Lactobacillus & $\begin{array}{l}\text { GAGGCAGCAGTAGGGAATCTTC } \\
\text { GGCCAGTTACTACCTCTATCCTTCTTC }\end{array}$ & Delroisse et al., $2008^{26}$ \\
\hline Fusobacterium & $\begin{array}{l}\text { CCCTTCAGTGCCGCAGT } \\
\text { GTCGCAGGATGTCAAGAC }\end{array}$ & Friswell et al., $2010^{27}$ \\
\hline Firmicutes & $\begin{array}{l}\text { ATGTGGTTTAATTCGAAGCA } \\
\text { AGCTGACGACAACCATGCAC }\end{array}$ & Guo et al., $2008^{25}$ \\
\hline Actinobacteria & $\begin{array}{l}\text { CGCGGCCTATCAGCTTGTTG } \\
\text { CCGTACTCCCCAGGCGGGG }\end{array}$ & Stach et al., $2003^{28}$ \\
\hline Bifidobacterium & $\begin{array}{l}\text { CTCCTGGAAACGGGTGG } \\
\text { GGTGTTCTTCCCGATATCTACA }\end{array}$ & Matsuki et al., $2002^{29}$ \\
\hline Prevotella & $\begin{array}{l}\text { GGTTCTGAGAGGAAGGTCCCC } \\
\text { TCCTGCACGCTACTTGGCTG }\end{array}$ & Bekele et al., $2010^{30}$ \\
\hline Enterococcus & $\begin{array}{l}\text { CCCTTATTGTTAGTTGCCATCATT } \\
\text { ACTCGTTCTTCCCATGT }\end{array}$ & Rinttila et al., $2004^{31}$ \\
\hline Proteobacteria & $\begin{array}{l}\text { CATGACGTTACCCGCAGAAGAAG } \\
\text { CTCTACGAGACTCAAGCTTGC }\end{array}$ & Friswell et al., $2010^{27}$ \\
\hline $\begin{array}{l}\text { Clostridium } \\
\text { Cluster IV }\end{array}$ & $\begin{array}{l}\text { GCACAAGCAGTGGAGT } \\
\text { CTTCCTCCGTTTTGTCAA }\end{array}$ & Matsuki et al., $2004^{29}$ \\
\hline Eggerthella lenta & $\begin{array}{l}\text { TGGCGAACGGGTGAGTAA } \\
\text { AGGCCCGGGAA CGTATTCAC }\end{array}$ & Lau et al., $2004^{32}$ \\
\hline Blautia coccoides-Eubacterium rectale group & CGGTACCTGACTAAGAAGC AGTTTCATTCTTGCGAACG & Rinttila et al., $2004^{31}$ \\
\hline Clostridium histolyticum group & ATGCAAGTCGAGCGA(G/T)G TATGCGGTATTAATCT(C/T)CCTTT & Rinttila et al., $2004^{31}$ \\
\hline Bacteroides uniformis & $\begin{array}{l}\text { TCCGTTTTCCACTTATAAGA } \\
\text { GGGTTBCCCCATTCGG }\end{array}$ & Liu et al., $2003^{33}$ \\
\hline Parabacteroides distasonis & TGCCTATCAGAGGGGGATAAC GCAAATATTCCCATGCGGGAT & Tong et al., $2011^{34}$ \\
\hline $\begin{array}{l}\text { Escherichia coli } \\
\text { Enterobacter cloacae } \\
\text { Faecalibacterium prausnitzii } \\
\text { Roseburia }\end{array}$ & $\begin{array}{l}\text { GACTGCAAAGACGTATGTAGATTCG ATCTATCCCTCTGACATCAACTGC } \\
\text { CGAGAGCCTGUTGCTG GAT TGGCTGACCCAAT } \\
\text { GGAGGAAGAAGGTCTTCGG AATTCCGCCTACCTCTGCACT } \\
\text { TACTGCATTGGAAACTGTCG CGGCACCGAAGAGCAAT }\end{array}$ & $\begin{array}{l}\text { Sharma et al., } 1999^{35} \\
\text { Anbazhagan } \text { et al., } 2010^{36} \\
\text { Payne } \text { et al., } 2011^{37} \\
\text { Larsen } \text { et al., } 2010^{38}\end{array}$ \\
\hline
\end{tabular}

created using serial tenfold dilution of pure cultures of DNA, corresponding to $10^{1}-10^{10}$ copies per gram of feces. The different strains used were obtained from the Spanish Collection of Type Cultures (CECT) (Bacteroides vulgatus NCTC 11154, Fusobacterium varium NCTC 10560, Enterococcus faecalis CECT 184, Enterobacter cloacae CECT 194, Clostridium perfringens CECT 376) and the American Collection of Type Cultures (ACTC) (Bifidobacterium bifidum ATCC 15696, Lactobacillus casei ATCC 334D-5, Prevotella intermedia ATCC 25611D-5, Clostridium histolyticum, ATCC 19401, Eggerthella lenta, ATCC 25559, Bacteroides uniformis ATCC8492, Ruminococcus productus, ATCC 27340D-5, Faecalibacterium prausnitzii (ATCC 27768) and Leibniz-Institut DSMZ (Roseburia intestinalis L1-82). The data presented are the mean values of duplicate real-time PCR analyses.

\section{Red wine composition}

The red wine and de-alcoholized red wine used in this study were elaborated with the Merlot grape variety, from the Penedes appellation. The de-alcoholized red wine had the same composition and polyphenolic compounds as the red wine, except for the ethanol. ${ }^{14}$ The phenolic profile of the red wine was determined by HPLC with diode-array detection as described previously ${ }^{39}$ and the resveratrol and piceid contents were determined by HPLC with diode-array detection as described by Romero-Pérez et al. ${ }^{40}$ The description of the daily alcohol and polyphenol consumption from the $272 \mathrm{~mL}$ of red wine and de-alcoholized red wine used in this study is shown in Table 2.

\section{Statistical analysis}

Results are expressed as mean values and standard deviations. The statistical analysis was performed with SPSS 15.0 software (SPSS Inc., Chicago, IL, USA). The 16S rRNA gene copy values were converted into logarithmic values before the statistical analysis. A Wilcoxon signed-rank test with a Bonferroni post hoc test was used to compare the treatments (changes in biochemical and anthropometric variables and in bacterial number) in each study group. The Mann-Whitney $U$ test was used to compare the MetS patients with the healthy subjects at baseline and after red wine and de-alcoholized red wine intake periods. One-way analysis of variance (ANOVA) for repeated 
Table 2 Daily polyphenol and alcohol consumption from $272 \mathrm{~mL}$ of red wine and $272 \mathrm{~mL}$ of de-alcoholized red wine used in this study

\begin{tabular}{|c|c|c|c|}
\hline & $\begin{array}{l}\text { De-alcoholized } \\
\text { red wine }\end{array}$ & Red wine & $P^{*}$ \\
\hline Total phenols (meq GA) ${ }^{a}$ & $733.02 \pm 23.61$ & $797.86 \pm 102.63$ & 0.426 \\
\hline \multicolumn{4}{|c|}{ Phenolic compounds $(\mathbf{m g})^{b}$} \\
\hline \multicolumn{4}{|l|}{ Flavan-3-ols } \\
\hline Catechin & $34.39 \pm 3.63$ & $33.60 \pm 3.07$ & 0.786 \\
\hline Epicatechin & $19.20 \pm 2.24$ & $18.46 \pm 2.11$ & 0.699 \\
\hline Procyanidin B1 & $17.50 \pm 2.10$ & $17.52 \pm 1.52$ & 0.712 \\
\hline Procyanidin B2 & $12.92 \pm 1.44$ & $12.41 \pm 0.74$ & 0.502 \\
\hline Procyanidin B3 & $7.48 \pm 0.08$ & $6.85 \pm 0.08$ & 0.526 \\
\hline Procyanidin B4 & $13.19 \pm 1.35$ & $13.33 \pm 1.54$ & 0.934 \\
\hline \multicolumn{4}{|l|}{ Anthocyanins } \\
\hline Delphinidin-3-glucoside & $4.00 \pm 0.44$ & $4.15 \pm 0.24$ & 0.589 \\
\hline Petunidin-3-glucoside & $3.27 \pm 0.31$ & $3.34 \pm 0.29$ & 0.755 \\
\hline Peonidin-3-glucoside & $1.82 \pm 0.16$ & $1.84 \pm 0.17$ & 0.797 \\
\hline Malvidin-3-glucoside & $13.56 \pm 1.16$ & $13.28 \pm 1.21$ & 0.787 \\
\hline Malvidin-(6-acetyl)- & $2.83 \pm 0.33$ & $2.98 \pm 0.26$ & 0.563 \\
\hline \multicolumn{4}{|l|}{ 3-glucoside } \\
\hline $\begin{array}{l}\text { Malvidin-(6-coumaroyl)- } \\
\text { 3-glucoside }\end{array}$ & $0.96 \pm 0.09$ & $1.13 \pm 0.07$ & 0.066 \\
\hline \multicolumn{4}{|l|}{ Flavonols } \\
\hline Quercetin-3-glucuronide & $3.06 \pm 0.39$ & $3.23 \pm 0.38$ & 0.770 \\
\hline Quercetin & $6.48 \pm 0.64$ & $7.25 \pm 0.21$ & 0.161 \\
\hline Isorhamnetin & $0.80 \pm 0.04$ & $0.91 \pm 0.07$ & 0.114 \\
\hline \multicolumn{4}{|l|}{ Hydroxycinnamic acids } \\
\hline 2-S-Glutathionylcaftaric & $2.93 \pm 0.34$ & $2.80 \pm 0.27$ & 0.956 \\
\hline trans-Caftaric & $5.23 \pm 0.44$ & $5.06 \pm 0.39$ & 0.595 \\
\hline trans-Caffeic & $3.31 \pm 0.25$ & $3.13 \pm 0.22$ & 0.246 \\
\hline trans-Coutaric & $1.53 \pm 0.14$ & $1.42 \pm 0.12$ & 0.182 \\
\hline \multicolumn{4}{|l|}{ Stilbenes } \\
\hline trans-Resveratrol & $0.74 \pm 0.06$ & $0.79 \pm 0.10$ & 0.352 \\
\hline cis-Resveratrol & $0.75 \pm 0.04$ & $0.76 \pm 0.04$ & 0.761 \\
\hline trans-Piceid & $2.86 \pm 0.26$ & $2.56 \pm 0.31$ & 0.160 \\
\hline cis-Piceid & $1.93 \pm 0.24$ & $2.10 \pm 0.09$ & 0.226 \\
\hline \multicolumn{4}{|l|}{ Hydroxybenzoic acids } \\
\hline Gallic acid & $19.90 \pm 1.91$ & $18.63 \pm 1.74$ & 0.306 \\
\hline Protocatechuic acid & $1.59 \pm 0.14$ & $1.42 \pm 0.17$ & 0.246 \\
\hline \multicolumn{4}{|l|}{ Tyrosols } \\
\hline Tyrosol & $13.01 \pm 1.06$ & $11.86 \pm 1.29$ & 0.298 \\
\hline Alcoholic content $(\mathrm{g})$ & $<1$ & 30 & \\
\hline \multicolumn{4}{|c|}{$\begin{array}{l}{ }^{*} \text { Comparison between red wine and de-alcoholized red wine } \\
\text { polyphenols (Student's } t \text {-test for independent samples). }{ }^{a} \text { Total } \\
\text { polyphenols: expressed as mean } \pm \mathrm{SD}(n=2) \text { milliequivalents of gallic } \\
\text { acid (meq GA). }{ }^{b} \text { Results are expressed as mean } \pm \text { SD }(n=2) \text { mg per } \\
\text { dose except for alcoholic content. }\end{array}$} \\
\hline
\end{tabular}

measures with the Bonferroni post hoc test was used to compare changes in the dietary analysis in response to the intervention treatments in each study group. Student's $t$-test for independent samples was used to analyze changes in dietary analysis between the MetS patients and the healthy subjects at baseline and after the two red wine intake periods. The Spearman correlation coefficient was calculated to estimate the linear correlations between variables. A multivariate regression analysis was performed to identify individual bacteria as independent predictors for blood pressure, plasma lipid profile and inflammation markers in both study groups after the polyphenol interventions (red wine and de-alcoholized red wine). Statistical significance was set at a $P$ value of $<0.05$.

\section{Results}

\section{Anthropometric and biochemical measurements}

The biochemical and anthropometric characteristics of the patients and controls are shown in Table 3. As expected, subjects in the MetS group had a significantly higher weight, waist and hip circumferences, BMI, DBP, SBP, glucose, GGT, triglycerides, total cholesterol, CRP and LPS and significantly lower HDL cholesterol than the healthy subjects at baseline. On the other hand, in the MetS group, after the red wine and de-alcoholized red wine intake periods, we observed a statistically significant decrease in the SBP, DBP, glucose, triglycerides, total cholesterol, CRP and LPS and a significant increase in the serum level of HDL cholesterol with respect to baseline. Nevertheless, the healthy subjects exhibited a significant decrease in the levels of GPT and plasma cholesterol after the red wine and de-alcoholized red wine intake periods with respect to baseline. No significant differences in the anthropometric and biochemical variables were found when comparing the red wine and de-alcoholized red wine intake periods within the MetS patients and the healthy groups. Finally, after the red wine and de-alcoholized red wine intake periods we only found significant differences in weight, waist and hip circumferences, BMI, GGT and triglycerides between the two study groups (Table 3).

\section{Diet and intervention compliance}

The red wine and de-alcoholized red wine were well tolerated by all the volunteers, who all completed the study, and no intolerance or adverse events were reported. No significant differences in dietary intake data were found during the study in the MetS patients and healthy subjects or between the two study groups at the basal level and in the different intake periods (Table 4 ).

Resveratrol metabolites derived from phase II metabolism and dihydroresveratrol produced by intestinal microbiota were significantly increased in urine after both red wine intakes compared to the basal level.

After red wine and de-alcoholized red wine intake, resveratrol metabolites were significantly increased compared to baseline $[4.49 \mu \mathrm{mol}(95 \% \mathrm{CI}: 1.36,7.63)]$ and $[5.03 \mu \mathrm{mol}(95 \% \mathrm{CI}$ : $2.25,7.80)](P<0.001)$ respectively. Total dihydroresveratrol after de-alcoholized red wine and red wine intake were also significantly increased compared with baseline $3.58 \mu \mathrm{mol}(95 \%$ CI: $1.18,6.17)$ and $4.57 \mu \mathrm{mol}(95 \% \mathrm{CI}: 0.42,8.79)$, respectively $(P<0.001)$.

Alcoholic intake was monitored after the two treatments by urinary ethylglucuronide output. After red wine intake the urinary ethylglucuronide concentration was significantly increased compared with baseline [358\% (95\% CI: 146, 570\%) $(P<0.05)]$. Nevertheless, no significant differences in urinary 
Table 3 Anthropometric and biochemical variables, during the study, of MetS patients and healthy subjects

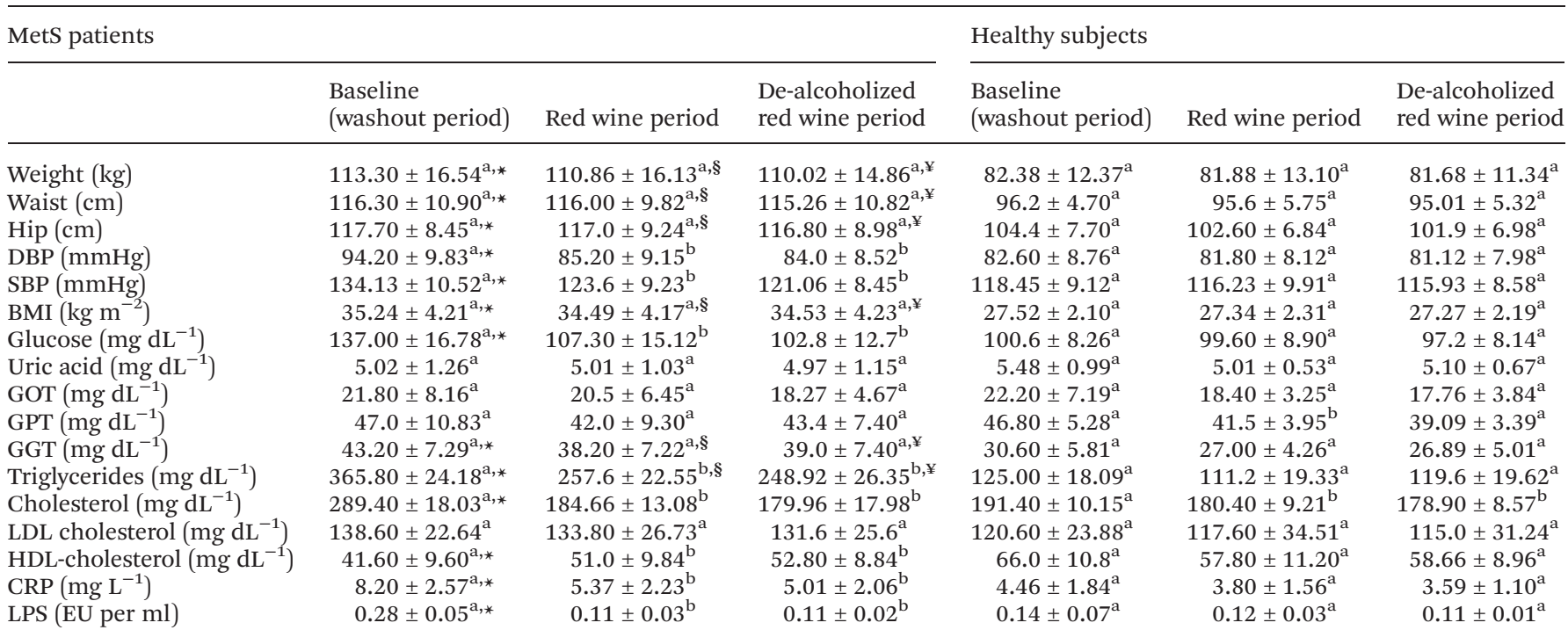

Values are presented as means $\pm \mathrm{SD} . N=10$ subjects per group. DBP, diastolic blood pressure, SBP, systolic blood pressure; GGT, gammaglutamyl transferase; GOT, glutamic oxaloacetic transaminase; GPT, glutamic pyruvic transaminase, CRP, C reactive protein. Values in a row with different superscript letters are significantly different $P<0.05$. ${ }^{*}$ Differences between MetS patients and healthy subjects at baseline $P<0.05$. ${ }^{\S}$ Differences between MetS patients and healthy subjects after red wine intake $P<0.05$. ${ }^{\ddagger}$ Differences between MetS patients and healthy subjects after de-alcoholized red wine intake $P<0.05$.

Table 4 Results of energy and dietary intakes in MetS patients and healthy subjects at baseline and after the red wine and de-alcoholized red wine intake periods

\begin{tabular}{|c|c|c|c|c|c|c|c|c|}
\hline \multicolumn{5}{|l|}{ MetS patients } & \multicolumn{4}{|l|}{ Healthy subjects } \\
\hline Energy $\left(\mathrm{kcal} \mathrm{d}^{-1}\right)$ & $2007.7 \pm 340.5^{\mathrm{a}}$ & $1919.8 \pm 376.2^{\mathrm{a}}$ & $1915.3 \pm 332.0^{\mathrm{a}}$ & 0.392 & $1978.5 \pm 368.0^{\mathrm{a}}$ & $1930.7 \pm 313.1^{\mathrm{a}}$ & $1985.3 \pm 360.2^{\mathrm{a}}$ & 0.772 \\
\hline Total protein $\left(\mathrm{g} \mathrm{d}^{-1}\right)$ & $71.2 \pm 22.2^{\mathrm{a}}$ & $70.8 \pm 28.4^{\mathrm{a}}$ & $69.5 \pm 30.0^{\mathrm{a}}$ & 0.126 & $70.7 \pm 27.2^{\mathrm{a}}$ & $69.7 \pm 20.8^{\mathrm{a}}$ & $68.6 \pm 28.8^{\mathrm{a}}$ & 0.888 \\
\hline Carbohydrates $\left(\mathrm{g} \mathrm{d}^{-1}\right)$ & $170.8 \pm 66.0^{\mathrm{a}}$ & $165.2 \pm 64.5^{\mathrm{a}}$ & $163.9 \pm 57.1^{\mathrm{a}}$ & 0.345 & $167.0 \pm 63.2^{\mathrm{a}}$ & $165.2 \pm 67.7^{\mathrm{a}}$ & $166.8 \pm 70.1^{\mathrm{a}}$ & 0.633 \\
\hline Total lipids $\left(\mathrm{g} \mathrm{d}^{-1}\right)$ & $81.5 \pm 33.6^{\mathrm{a}}$ & $80.7 \pm 32.1^{\mathrm{a}}$ & $79.9 \pm 36.2^{\mathrm{a}}$ & 0.661 & $77.8 \pm 37.6^{\mathrm{a}}$ & $76.7 \pm 40.3^{\mathrm{a}}$ & $77.6 \pm 42.8^{\mathrm{a}}$ & 0.942 \\
\hline Total polyphenols $\left(\mathrm{mg} \mathrm{d}^{-1}\right)$ & $409.0 \pm 97.3^{\mathrm{a}}$ & $390.5 \pm 89.3^{\mathrm{a}}$ & $381.9 \pm 92.8^{\mathrm{a}}$ & 0.749 & $391.5 \pm 86.9^{\mathrm{a}}$ & $393.6 \pm 98.6^{\mathrm{a}}$ & $387.7 \pm 77.4^{\mathrm{a}}$ & 0.921 \\
\hline
\end{tabular}

Values are presented as mean $\pm \mathrm{SD} . N=10$ subjects per group. Energy, nutrient and total polyphenol contributions from interventions were excluded. ${ }^{*}$ Changes in outcome variables in response to the intervention treatment were determined by repeated-measures 1 -factor ANOVA. $P<0.05$ (Bonferroni post hoc test). A Student's $t$-test for independent samples was used to look for the differences between groups. Different superscript letters are significantly different $(P<0.05)$.

ethylglucuronide concentration were observed between dealcoholized red wine and baseline [36\% (95\% CI: 25, 47\%) $(P=0.638)]$. Compliance with the red wine intervention was ensured by empty bottles returned and analyzing the participants' reports.

\section{PCR-DGGE fingerprint analysis and bacterial band identification in the fecal samples}

Variations were found in the presence or absence (qualitative) and intensity (quantitative) of the bands at baseline with respect to the red wine period in both the MetS patients and the healthy subjects in the host-specific fingerprints. DGGE band profiles showed differences in band richness between the two groups. Analyzing the diversity of microbiota, we found that at baseline there was a significant difference in the mean DGGE bands between the MetS patients and the healthy subjects $(11.4 \pm 1.3$ vs. $15.9 \pm 1.4 ; P<0.001)$. However, after the red wine and de-alcoholized red wine periods the differences in band richness between the MetS patients and the healthy subjects were not significant $(17.4 \pm 1.8$ vs. $17.9 \pm 1.6, P=$ 0.520 and $18.2 \pm 1.5$ vs. $18.6 \pm 1.4, P=0.545$, respectively). On the other hand, some bands were observed in fingerprints 
from all the periods (in a different lane but at the same position), indicating that specific species of the predominant microbiota were common to all groups.

The Dice similarity coefficient was used to calculate the similarity index of the DGGE band profiles for the two participant groups after the red wine and de-alcoholized red wine intake periods. The mean similarity index in the MetS patients was $29.6 \pm 7.13 \%$ and $30.1 \pm 7.42 \%$ respectively and in healthy subjects it was $27.08 \pm 8.07 \%$ and $28.1 \pm 7.75 \%$ respectively, with no significant differences between the study groups during these two intervention periods $(P=0.469$ and $P=$ 0.563).

All the bands from all subject profiles at baseline and after the red wine and de-alcoholized red wine periods in the two study groups were cloned and sequenced to identify the dominant microbiota and the sequence similarity matches for bands were analyzed by using MicroSeqID v2.1.1 software. Bacterial identification showed that the majority of the bacteria represented in our fingerprints corresponded to four phyla (Table 4). Most of the sequences belonged to Firmicutes and Bacteroidetes, with the rest distributed among Actinobacteria and Proteobacteria. Nevertheless, we also observed important differences between the MetS patients and the healthy subjects in the frequencies of different genera within these phyla at baseline. In the MetS patients at baseline, we found an increase in the frequencies of Bacteroides, Clostridium and Escherichia accompanied by a decrease in the frequencies of Prevotella and the absence of Lactobacillus and Bifidobacterium with respect to healthy subjects. Finally, after red wine and dealcoholized red wine intake we found no differences in the frequency of appearance at different taxa levels between both the study groups (Table 5).
Comparative analysis of gut microbiota communities between the MetS patients and healthy subjects at baseline and after the red wine and de-alcoholized red wine intake periods

Changes in the bacterial population abundance at the phylum and genus levels were assessed in the fecal samples of the two study groups at baseline and after each intervention period (Table 6). At baseline, a significant increase in the number of Proteobacteria and Firmicutes was found in the MetS patients with respect to the healthy subjects, while after the red wine and de-alcoholized red wine intake periods no significant differences at the phylum level were found between the study groups. Nevertheless, in the MetS subjects we observed a significant increase in the number of Fusobacteria and Bacteroidetes and a significant decrease in Firmicutes after the red wine and de-alcoholized red wine periods with respect to baseline. Also, in the healthy group we observed a significant increase in Bacteroidetes when compared to baseline after both the red wine and the de-alcoholized red wine intake periods.

Within Firmicutes, in the MetS patients we found a significant decrease in the number of the Clostridium and the Clostridium histolyticum group accompanied by a significant increase in the quantities of the Blautia coccoides-Eubacterium rectale group, Faecalibacterium prausnitzii, Roseburia and Lactobacillus after the red wine and de-alcoholized red wine intake periods compared to baseline. In the healthy group we have only observed a significant increase in the number of Faecalibacterium prausnitzii and Roseburia through the intervention study. Moreover, the significant differences in the bacteria number of the Blautia coccoides-Eubacterium rectale group, Clostridium, Clostridium histolyticum group and Lactobacillus observed at the baseline level between the study groups disappeared after the two red wine intervention periods.

Table 5 Bacterial identification after the sequencing of the bands from the DGGE analysis of fecal samples at baseline and after the red wine and de-alcoholized red wine intake periods in both study groups

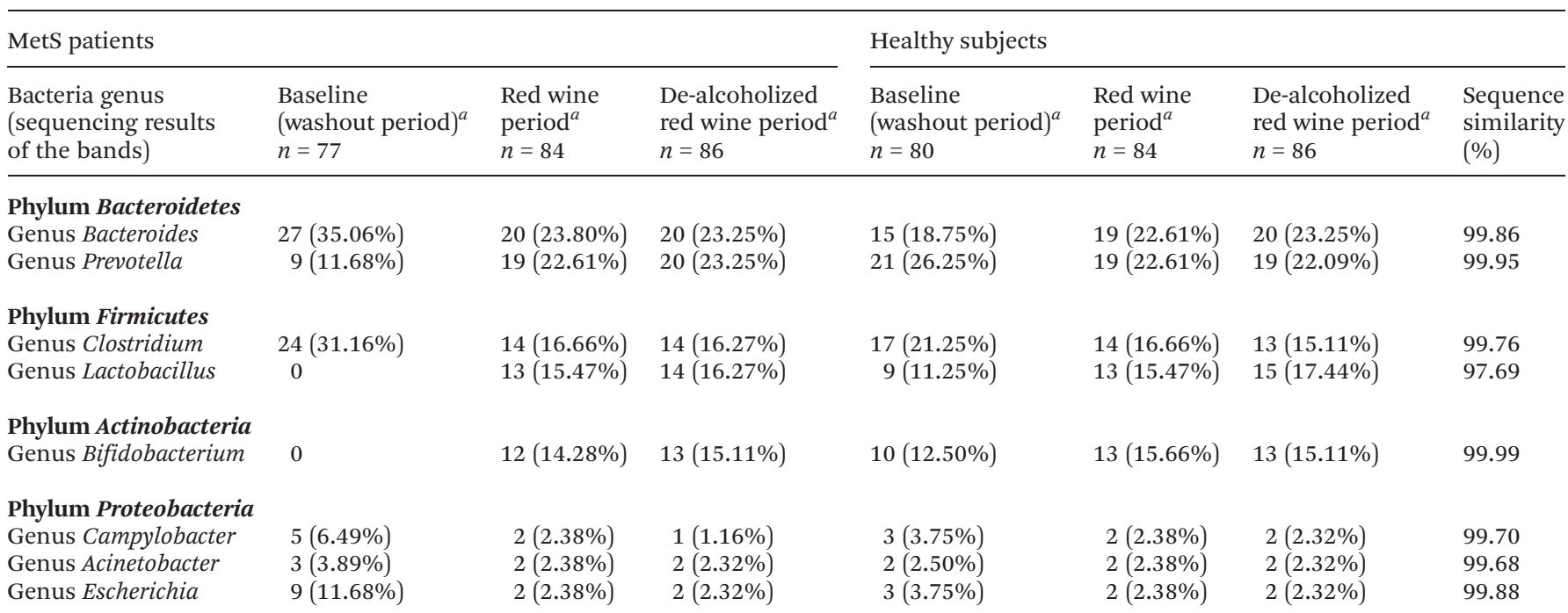

${ }^{a}$ Refers to the frequency (and percent) of each unique bacteria genus in the baseline or red wine or de-alcoholized red wine intake periods. " $n$ " refers to the number of bands cloned, sequenced and identified in each study group. $N=10$ subjects per group. 
Table 6 Real-time quantitative PCR of microbiota phyla, genera, groups and species in both study groups. The absence of superscripts $\S$ and $¥$ in the table indicate no significant differences

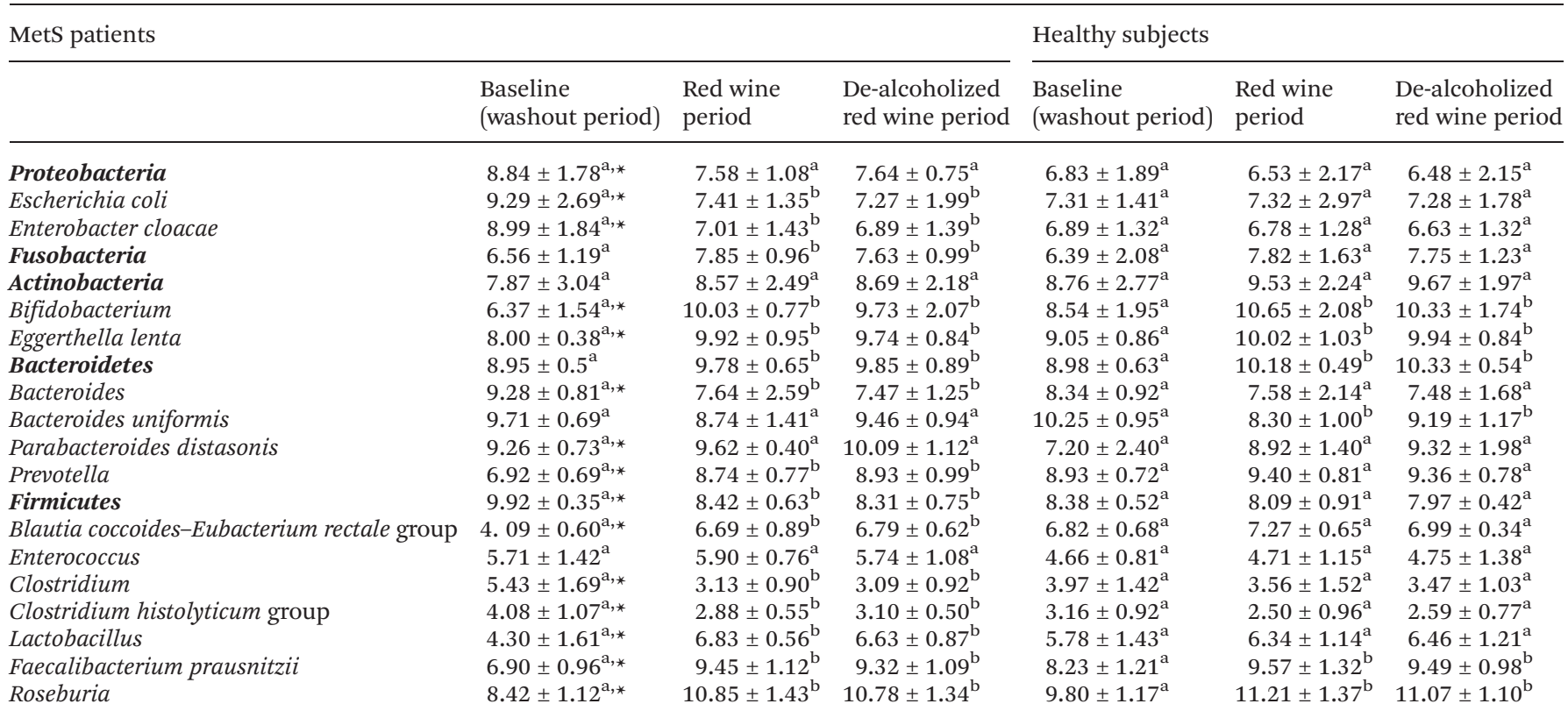

Values are presented as means $\pm \mathrm{SD}$ and expressed as $\log _{10}$ copies per gram of feces. $N=10$ participants per group. Values in a row with different superscript letters are significantly different $P<0.05$. ${ }^{*}$ Differences between MetS patients and healthy subjects at baseline $P<0.05 .{ }^{\S}$ Differences between MetS patients and healthy subjects after red wine intake $P<0.05$. ${ }^{\ddagger}$ Differences between MetS patients and healthy subjects after dealcoholized red wine intake $P<0.05$.

Within Bacteroidetes, a significant decrease in the number of Bacteroides and a significant increase in Prevotella were observed in the MetS group after red wine and de-alcoholized red wine intake compared to baseline. Similarly, in the healthy group, a significant decrease in the number of Bacteroides uniformis was found only when compared to baseline after the red wine and de-alcoholized red wine periods. In addition, at baseline we found a significantly higher quantity of Bacteroides and Parabacteroides distasonis and a lower number of Prevotella in the MetS group with respect to the healthy group. Nevertheless no difference was observed after the two red wine intake periods when compared to the study groups.

Within Actinobacteria significant increases in the number of Bifidobacterium and Eggerthella lenta were observed in the MetS patients and healthy subjects after the red wine and de-alcoholized red wine periods with respect to baseline. The significant difference found at the basal level in these two genera when compared to the MetS patients and healthy volunteers was not seen after the red wine and de-alcoholized red wine periods.

Finally, at baseline, within Proteobacteria we observed a significant increase in the number of Escherichia coli and Enterobacter cloacae in the MetS group compared to healthy subjects, but these significant differences disappeared after the red wine intake periods. Moreover, in the MetS group, a significant decrease in the number of Escherichia coli and Enterobacter cloacae was observed after the red wine and de-alcoholized red wine intake with respect to the baseline period. No significant differences were found in the healthy subjects in the quantity of Escherichia coli and Enterobacter cloacae when compared to baseline after the red wine intake periods.

\section{Relationship between gut microbiota composition and blood pressure, plasma glucose level, plasma lipid profile and inflammation markers in both study groups}

After the polyphenol interventions (red wine and de-alcoholized red wine), in the MetS patients we found a significant univariate correlation between changes in the amount of specific bacteria at different taxa levels and plasma triglycerides, cholesterol, HDL-cholesterol, glucose and CRP (Table 7). In the healthy subjects, however, we only observed significant univariate correlations between changes in the amount of specific bacteria and HDL-cholesterol, glucose and SBP (Table 8).

In the MetS group, using a multivariate regression analysis that included all the bacterial groups analyzed, only the increase in Actinobacteria $\left(P=0.005, \beta=1.11, R^{2}=0.99\right)$ and Lactobacillus $\left(P<0.001, \beta=0.224, R^{2}=0.99\right)$ and the decrease in Clostridium histolyticum $\left(P=0.029, \beta=-0.194, R^{2}=0.99\right)$ and Escherichia coli $\left(P=0.029, \beta=-0.194, R^{2}=0.99\right)$ predicted the triglyceride reduction. Moreover, the increases in the numbers of Bifidobacterium $\left(P=0.001, \beta=1.004, R^{2}=0.99\right)$ and Faecalibacterium prausnitzii $\left(P=0.001, \beta=1.10, R^{2}=0.99\right)$ were associated with the reductions in plasma cholesterol and glucose levels respectively. On the other hand, the decrease in CRP was predicted by the decrease in Clostridium $(P=0.040$, $\left.\beta=-0.762 R^{2}=0.97\right)$, and the reduction in plasma LPS levels was associated with Bifidobacterium growth $(P=0.015$, 
Table 7 Correlations between gut microbiota composition and blood pressure, glucose level, plasma lipid profile and inflammation markers in MetS patients

\begin{tabular}{|c|c|c|c|c|c|c|}
\hline & Triglycerides & Cholesterol & HDL-cholesterol & LPS & CRP & Glucose \\
\hline Clostridium & $0.882(0.048)$ & & & & $0.882(0.048)$ & \\
\hline Lactobacillus & $-0.915(0.030)$ & $-0.992(0.007)$ & & & & \\
\hline Bacteroidetes & $-0.916(0.029)$ & & & & & \\
\hline Bacteroides uniformis & & $-0.956(0.011)$ & & & & \\
\hline Bifidobacterium & & $-0.908(0.033)$ & $0.917(0.028)$ & $-0.906(0.034)$ & & \\
\hline Faecalibacterium prausnitzii & & & & & & $-0.997(0.001)$ \\
\hline Roseburia & & & & & & $-0.937(0.030)$ \\
\hline
\end{tabular}

Table 8 Correlations between gut microbiota composition and blood pressure, glucose level and plasma lipid profile in healthy subjects

\begin{tabular}{lcc}
\hline & HDL-cholesterol & SBP \\
\hline Proteobacteria & $-0.945(0.015)$ & $0.912(0.031)$ \\
Blautia coccoides-Eubacterium rectale group & $0.946(0.015)$ & $0.982(0.003)$ \\
Clostridium & $-0.904(0.035)$ & $-0.908(0.003)$ \\
Lactobacillus & & $-0.907(0.032)$
\end{tabular}

Correlations are reported by Spearman's Rho $(r)$ and $P$-values are given in parentheses. Statistical significance was set at a $P$ value of $<0.05$.

$\left.\beta=0.342, R^{2}=0.750\right)$ and the decrease in the number of Enterobacter cloacae $\left(P=0.032, \beta=-0.564, R^{2}=0.98\right)$. In the healthy group, after a multivariate regression analysis, only the decrease in Clostridium was associated with the decrease in $\operatorname{SBP}\left(P=0.001, \beta=-1.019, R^{2}=0.99\right)$.

\section{Discussion}

In the current study we have shown that the differences in the composition of fecal microbiota found between the MetS patients and the healthy subjects disappeared after a regular intake of red wine and de-alcoholized red wine polyphenols during one month. Specifically, there was a significant increase in the abundance of intestinal barrier protectors and butyrate-producing bacteria and a significant decrease in LPS producers in the MetS group after polyphenol interventions (red wine and de-alcoholized red wine). In order to analyze the fecal microbiota characteristics under MetS conditions, as well as to observe the effect of red wine polyphenols on this microbiota, we had to exclude the influence of confounding factors such as age, gender, diet and race from this study.

PCR-DGGE was used to analyze the predominant fecal bacterial populations in order to compare the bacterial diversity and similarity between the two study groups after the red wine and de-alcoholized red wine intake periods. The results revealed that the diversity and similarity of the dominant bacterial composition in the MetS patients were not significantly different from those of the healthy subjects after the two red wine interventions.

Sequence analysis of all DGGE bands obtained allowed the association of specific bacterial genotypes with the MetS or a healthy status. Previous studies have shown the dominance of Bacteroidetes, Firmicutes and Proteobacterias in the feces of both groups of subjects. The main differences found were at the genus-division of bacteria within these phyla at baseline between the MetS patients and the healthy subjects. We found that within Bacteroidetes, the Prevotella genus was associated with healthy subjects, while the Bacteroides genus was prevalent in the MetS group. Given the concept of "enterotypes", i.e., the assignment of an individual microbiome to a given enterotype based upon the relative enrichment of that microbiome in one of the three genera: Bacteroides (enterotype 1), Prevotella (enterotype 2) or Ruminococcus (enterotype $3),{ }^{41}$ the MetS gut microbiomes could be classified into enterotype 1 and the healthy microbiomes could be classified into enterotype 2. In addition, the apparent baseline association between the Escherichia genus and the MetS group, as well as the lack of Bifidobacterium and Lactobacillus genera in the same group, is noteworthy. However, after the intake of red wine and de-alcoholized red wine, the dominant microbiota genera were not significantly different in the MetS patients compared to healthy subjects, demonstrating the prebiotic capacity of the red wine polyphenols, able to change the dominant microbiota community associated with the MetS conditions. 
As DGGE is considered a semi-quantitative tool for monitoring the dynamics of the predominant bacterial species of fecal microbiota, an additional analysis with real-time quantitative PCR was performed to obtain a quantitative estimation of the changes found in the gut microbiota between the MetS patients and healthy subjects at baseline and after the red wine and de-alcoholized red wine intake periods. We found that at baseline the MetS patients had a significantly lower number of Bifidobacterium, Eggerthella lenta, Prevotella, Blautia coccoides-Eubacterium rectale group, Lactobacillus, Faecalibacterium prausnitzii and Roseburia and significantly more Proteobacteria, Firmicutes, Escherichia coli, Enterobacter cloacae, Bacteroides, Parabacteroides distasonis, Clostridium spp. and Clostridium histolitycum in their gut microbiota compared to healthy subjects. After the polyphenol interventions (red wine and de-alcoholized red wine), however, we found no significant differences in the microbiota between the two study groups.

After the red wine and de-alcoholized red wine intake periods, in the MetS patients we observed a significant decrease in Bacteroides and a significant increase in protectors of the gut mucosal barrier, such as Bifidobacterium spp. and Lactobacillus spp., possibly due to their capacity to degrade phenolic compounds such as anthocyanin metabolites. ${ }^{42}$ Other studies by Vendrame et $a .^{43}$ and Hidalgo et $a{ }^{44}{ }^{44}$ also indicated that anthocyanins seemed to increase the number of Bifidobacterium spp. and Lactobacillus spp. in the human gut microbiota of healthy subjects. Moreover, previous studies have also suggested that dietary polyphenols may help to improve the growth of certain Lactobacillus strains, which may mitigate the inflammation by promoting the normalization of intestinal microflora and exclusion of pathogens, decreasing intestinal permeability, improving the intestine's immunological barrier functions and alleviating the intestinal inflammatory response. ${ }^{45}$

In addition, Hidalgo et al. ${ }^{44}$ investigated the effect of gallic acid, which is a structural component of ellagitannins, on human gut microflora, showing a clear inhibition of the growth of potentially harmful gut bacteria of the Clostridium histolyticum group, which includes important pathogens closely related to the progression of colon cancer and the onset of inflammatory bowel disease. Another intervention study with cocoa flavan-3-ols in healthy volunteers has shown that they enhance the growth of Lactobacillus spp. and Bifidobacterium spp. and limit the growth of the Clostridium histolyticum group. ${ }^{46}$ Similar results have been reported by us on the number of Clostridium histolyticum groups after red wine and de-alcoholized red wine intake periods in MetS patients, suggesting that red wine polyphenols have an inhibitory effect on the growth of these bacteria. Differences in the cell surface structures could explain why Gram-positive clostridial type bacteria are more sensitive to the bactericidal effects of these compounds that are Gram-negative species. ${ }^{47}$

At baseline, the MetS patients weighed significantly more than their healthy controls and after red wine and de-alcoholized red wine consumption, the MetS patients showed a greater reduction in body weight than healthy controls, although this reduction was not statistically significant. The weight decrease observed in this study is probably related to the alteration in the balance between the Bacteroidetes and Firmicutes groups in favor of Bacteroidetes, in part possibly due to the polyphenol content of the wine. This prevalence of Bacteroidetes found following regular wine ingestion (red wine and de-alcoholized red wine) could be due to Firmicutes possessing a disproportionately smaller number of glycan-degrading enzymes than Bacteroidetes, this being the possible mechanism by which polyphenols may exert their effect on lowering weight. ${ }^{48}$ Moreover, our results clearly showed that red wine and de-alcoholized red wine significantly decreased SBP and DBP in the MetS patients and these results agree with those of other studies, which have reported that polyphenols reduce elevated blood pressure. ${ }^{49}$

Interestingly, polyphenols and polyphenols plus ethanol significantly reduced the blood glucose levels in the MetS patients compared to baseline, possibly due to the shift in the gut microbiota to a higher proportion of Gram-positive relative to Gram-negative bacteria produced by the presence of polyphenols. It has been found that type 2 diabetes mellitus might be associated with the dominance of Gram-negative bacteria in the gut. ${ }^{50}$ This study has shown that polyphenol and polyphenol plus ethanol intake positively affected the growth of the Blautia coccoides-Eubacterium rectale group, Faecalibacterium prausnitzii and Roseburia the most abundant intestinal butyrate producing bacteria. Previous studies have shown that butyrate induces mucin synthesis, ${ }^{51}$ decreases bacterial transport across the epithelium, ${ }^{52}$ and improves gut integrity by increasing the tight junction assembly. ${ }^{53}$ Moreover, we have found that the increase in the abundance of Faecalibacterium prausnitzii was associated with the decrease in blood glucose levels in MetS patients. This association may be related to the role of the short-chain fatty acids such as butyrate formed by this gut microbiota in the regulation of the levels of gut hormones such as glucose-dependent insulinotropic polypeptide and glucagon-like peptide 1 , which have important effects on carbohydrate metabolism. ${ }^{54}$

In addition to this regulation in insulin sensitivity, we found that the regular intake of red wine, with or without ethanol, generated significant decreases in the plasma levels of triglycerides and total cholesterol and an increase in plasma levels of HDL-cholesterol in the MetS patients during the study. In this study, the decrease observed in the plasma cholesterol concentration could be related to the significant increase in Bifidobacterium induced by red wine polyphenols, a bacterial genus that has the capacity to produce beneficial organic acids (lactate and acetate) and the ability to inhibit the growth of pathogenic bacteria, ${ }^{55}$ and that has been previously associated with the reduction of plasma cholesterol levels. ${ }^{56,57}$ Moreover, we observed a negative association between the number of Bifidobacterium and the plasma cholesterol levels in the MetS patients in our study. Additionally, gut microbiota can increase energy metabolism and have a systemic effect on host lipid metabolism, especially increasing triglyceride clearance. ${ }^{58}$ 
On the other hand, the significant increase in the numbers of Eggerthella lenta (bacteria able to degrade resveratrol into dihydroresveratrol) found in both study groups was related to the significant enhancement of dihydroresveratrol found after de-alcoholized red wine and red wine intake with respect to baseline. Claus et al. showed an association between the genus Eggerthella and host metabolism and especially hepatic triglyceride levels in mice. ${ }^{59}$

Low grade inflammatory signaling has been suggested to be one of the mechanisms linking gut microbiota to the MetS. ${ }^{60}$ In our study we observed that LPS plasma concentrations were significantly increased two-fold in the MetS patients with respect to healthy subjects at baseline. This plasma endotoxin increase may derive from enhanced LPS production by gut microbiota (metabolic endotoxemia) or from increased intestinal LPS absorption. ${ }^{61}$ But after the red wine and de-alcoholized red wine intake periods the plasma endotoxin load (LPS) was significantly reduced, accompanied by a concomitant decrease in CRP (a well-defined biomarker for low-grade inflammation), resulting in an important alleviation of the inflammatory condition. This situation may be explained by the observed decrease in the number of lipopolysaccharide producers (Escherichia coli and Enterobacter cloacae) ${ }^{62}$ and the increase in intestinal barrier protectors such as Bifidobacterium spp. after the polyphenol and polyphenol plus ethanol intake periods in the MetS patients compared to the baseline level. Moreover, we found a significant negative and a significant positive association between Bifidobacterium spp. and Enterobacter cloacae, respectively, and the plasma level of LPS in the MetS patients. Similarly, Cani et al., ${ }^{60}$ using animal models, observed an inverse correlation between the number of Bifidobacterium and the LPS levels after a high-fat diet. These data show that changes in the gut microbiota produced by red wine and de-alcoholized red wine may cause a decrease in the release of LPS in the bloodstream of the host due to an enhancement of the intestinal barrier integrity produced by changes in the gut microbiota, improving insulin sensitivity and obesity in the MetS patients.

These study findings indicate that polyphenols or small ethanol doses plus polyphenol intake for a short time can generate an important change in the gut microbiota, which may influence the host metabolism. Moreover, we also observed that small ethanol doses did not block the polyphenols from doing their protective work.

\section{Conclusion}

A moderate intake of red wine by obese adults with the MetS resulted in positive effects on the composition of the gut microbiota and a reduction in the metabolic syndrome risk markers. Due to the dominating role of diet in shaping the composition of the gut microbiota, modulation of the gut microbiota by nutrients with prebiotic properties such as red wine could be an effective strategy for managing metabolic diseases associated with obesity.

\section{Abbreviations}

$\begin{array}{ll}\text { MetS } & \text { Metabolic syndrome } \\ \text { PCR-DGGE } & \begin{array}{l}\text { Polymerase chain reaction-denaturing gradient } \\ \text { gel electrophoresis }\end{array} \\ \text { CECT } & \text { Spanish collection of type cultures } \\ \text { ACTC } & \text { American collection of type cultures } \\ \text { DBP } & \text { Diastolic blood pressure } \\ \text { SBP } & \text { Systolic blood pressure } \\ \text { GGT } & \text { Gamma-glutamyl transferase } \\ \text { GOT } & \text { Glutamic oxaloacetic transaminase } \\ \text { GPT } & \text { Glutamic pyruvic transaminase } \\ \text { CRP } & \text { C reactive protein }\end{array}$

\section{Authors' contributions}

FC, FJT and MIQO: conception and design of the research; IMI, LSA, PPM, CAL, FC and MIQO: research work; IMI, FC and MIQO: statistical analysis and data interpretation; IMI, FC, FJT and MIQO wrote the paper, and PPM, CAL, FJT and MIQO provided critical revision.

\section{Conflict of interest statement}

All authors declare the absence of any conflict of interest.

\section{Acknowledgements}

The research group belongs to the "Centros de Investigación en Red" [CIBER, CB06/03/0018] of the "Instituto de Salud Carlos III". Isabel Moreno Indias was supported by a "Sara Borrell” postdoctoral contract (CD12/00530), María Isabel Queipo-Ortuño acknowledges support from the "Miguel Servet Type I" program (CP13/00065) and Fernando Cardona acknowledges support from the "Miguel Servet Type II" program (CP13/00023) from the Instituto de Salud Carlos III, Madrid, Spain, and co-founded by Fondo Europeo de Desarrollo Regional - FEDER. We are grateful to Torres S. A. for providing the red wine used in this study.

\section{References}

1 R. H. Eckel, S. M. Grundy and P. Z. Zimmet, Lancet, 2005, 365, 1415-1428.

2 H. Tilg and A. Kaser, J. Clin. Invest., 2011, 121, 2126-2132.

3 M. Vijay-Kumar, J. D. Aitken, F. A. Carvalho, T. C. Cullender, S. Mwangi, S. Srinivasan, S. V. Sitaraman, R. Knight, R. E. Ley and A. T. Gewirtz, Science, 2010, 328, 228-231.

4 N. M. Delzenne, A. M. Neyrinck and P. D. Cani, Microb. Cell Fact., 2011, 10, S10.

5 M. Roberfroid, G. R. Gibson, L. Hoyles, A. L. McCartney, R. Rastall, I. Rowland, D. Wolvers, B. Watzl, H. Szajewska, 
B. Stahl, F. Guarner, F. Respondek, K. Whelan, V. Coxam, M. J. Davicco, L. Leotoing, Y. Wittrant, N. M. Delzenne, P. D. Cani, A. M. Neyrinck and A. Meheust, Br. J. Nutr., 2010, 104, S1-63.

6 N. M. Delzenne, A. M. Neyrinck, F. Backhed and P. D. Cani, Nat. Rev. Endocrinol., 2011, 7, 639-646.

7 J. M. Hodgson and K. D. Croft, J. Sci. Food Agric., 2006, 86, 2492-2498.

8 F. Cardona, C. Andres-Lacueva, S. Tulipani, F. J. Tinahones and M. I. Queipo-Ortuno, J. Nutr. Biochem., 2013, 24, 14151422.

9 R. Puupponen-Pimia, T. Seppanen-Laakso, M. Kankainen, J. Maukonen, R. Torronen, M. Kolehmainen, T. Leppanen, E. Moilanen, L. Nohynek, A. M. Aura, K. Poutanen, F. A. Tomas-Barberan, J. C. Espin and K. M. OksmanCaldentey, Mol. Nutr. Food Res., 2013, 57, 2258-2263.

10 E. P. Cherniack, Nutrition, 2011, 27, 617-623.

11 I. Perez-Torres, A. Ruiz-Ramirez, G. Banos and M. El-Hafidi, Cardiovasc. Hematol. Agents Med. Chem., 2013, 11, 25-37.

12 N. Osakabe, J. Clin. Biochem. Nutr., 2013, 52, 186-192.

13 A. Agouni, A. H. Lagrue-Lak-Hal, H. A. Mostefai, A. Tesse, P. Mulder, P. Rouet, F. Desmoulin, C. Heymes, M. C. Martinez and R. Andriantsitohaina, PLoS One, 2009, 4, e5557.

14 M. I. Queipo-Ortuño, M. Boto-Ordoñez, M. Murri, J. M. Gomez-Zumaquero, M. Clemente-Postigo, R. Estruch, F. Cardona Diaz, C. Andres-Lacueva and F. J. Tinahones, Am. J. Clin. Nutr., 2012, 95, 1323-1334.

15 M. Larrosa, M. J. Yanez-Gascon, M. V. Selma, A. GonzalezSarrias, S. Toti, J. J. Ceron, F. Tomas-Barberan, P. Dolara and J. C. Espin, J. Agric. Food Chem., 2009, 57, 2211-2220.

16 R. Puupponen-Pimia, L. Nohynek, S. Hartmann-Schmidlin, M. Kahkonen, M. Heinonen, K. Maatta-Riihinen and K. M. Oksman-Caldentey, J. Appl. Microbiol., 2005, 98, 9911000.

17 L. J. Nohynek, H. L. Alakomi, M. P. Kahkonen, M. Heinonen, I. M. Helander, K. M. Oksman-Caldentey and R. H. Puupponen-Pimia, Nutr. Cancer, 2006, 54, 18-32.

18 X. Tzounis, J. Vulevic, G. G. Kuhnle, T. George, J. Leonczak, G. R. Gibson, C. Kwik-Uribe and J. P. Spencer, Br. J. Nutr., 2008, 99, 782-792.

19 R. H. Eckel, J. M. Jakicic, J. D. Ard, J. M. de Jesus, N. Houston Miller, V. S. Hubbard, I. M. Lee, A. H. Lichtenstein, C. M. Loria, B. E. Millen, C. A. Nonas, F. M. Sacks, S. C. Smith Jr., L. P. Svetkey, T. A. Wadden, S. Z. Yanovski, K. A. Kendall, L. C. Morgan, M. G. Trisolini, G. Velasco, J. Wnek, J. L. Anderson, J. L. Halperin, N. M. Albert, B. Bozkurt, R. G. Brindis, L. H. Curtis, D. DeMets, J. S. Hochman, R. J. Kovacs, E. M. Ohman, S. J. Pressler, F. W. Sellke, W. K. Shen, S. C. Smith Jr., G. F. Tomaselli and American College of Cardiology/ American Heart Association Task Force on Practice Guidelines, Circulation, 2014, 129, S76-S99.

20 C. W. Callaway, in: The Airlie (VA) Consensus ConferenceStandardization of anthropometric measurements, ed. T. Loham,
A. Roche and R. Martorel, Human Kinetics, Champaign, IL, USA, 1988, pp. 20-37.

21 R. Zamora-Ros, M. Urpi-Sarda, R. M. Lamuela-Raventos, R. Estruch, M. Vazquez-Agell, M. Serrano-Martinez, W. Jaeger and C. Andres-Lacueva, Clin. Chem., 2006, 52, 1373-1380.

22 R. U. S. M. Zamora-Ros, R. M. Lamuela-Raventós, R. Estruch, M. A. Martínez-González, M. Bulló, F. Arós, A. Cherubini and C. Andres-Lacueva, Free Radicals Biol. Med., 2009, 46, 1562-1566.

23 M. Urpi-Sarda, R. Zamora-Ros, R. Lamuela-Raventos, A. Cherubini, O. Jauregui, R. de la Torre, M. I. Covas, R. Estruch, W. Jaeger and C. Andres-Lacueva, Clin. Chem., 2007, 53, 292-299.

24 M. E. Juan, I. Alfaras and J. M. Planas, J. Agric. Food Chem., 2010, 58, 7472-7475.

25 X. Guo, X. Xia, R. Tang, J. Zhou, H. Zhao and K. Wang, Lett. Appl. Microbiol., 2008, 47, 367-373.

26 J. M. Delroisse, A. L. Boulvin, I. Parmentier, R. D. Dauphin, M. Vandenbol and D. Portetelle, Microbiol. Res., 2008, 163, 663-670.

27 M. K. Friswell, H. Gika, I. J. Stratford, G. Theodoridis, B. Telfer, I. D. Wilson and A. J. McBain, PLoS One, 2010, 5, e8584.

28 J. E. Stach, L. A. Maldonado, A. C. Ward, M. Goodfellow and A. T. Bull, Environ. Microbiol., 2003, 5, 828-841.

29 T. Matsuki, K. Watanabe, J. Fujimoto, T. Takada and R. Tanaka, Appl. Environ. Microbiol., 2004, 70, 7220-7228.

30 A. Z. Bekele, S. Koike and Y. Kobayashi, FEMS Microbiol. Lett., 2010, 305, 49-57.

31 T. Rinttila, A. Kassinen, E. Malinen, L. Krogius and A. Palva, J. Appl. Microbiol., 2004, 97, 1166-1177.

32 S. K. Lau, P. C. Woo, G. K. Woo, A. M. Fung, M. K. Wong, K. M. Chan, D. M. Tam and K. Y. Yuen, Diagn. Microbiol. Infect. Dis., 2004, 49, 255-263.

33 C. Liu, Y. Song, M. McTeague, A. W. Vu, H. Wexler and S. M. Finegold, FEMS Microbiol. Lett., 2003, 222, 9-16.

34 J. Tong, C. Liu, P. Summanen, H. Xu and S. M. Finegold, Anaerobe, 2011, 17, 64-68.

35 V. K. Sharma, E. A. Dean-Nystrom and T. A. Casey, Mol. Cell Probes., 1999, 13, 291-302.

36 D. Anbazhagan, G. G. Kathirvalu, M. Mansor, G. O. S. Yan, M. Y. Yusof and S. D. Sekaran, Afr. J. Microbiol. Res., 2010, 4, 1186-1191.

37 A. N. Payne, C. Chassard, M. Zimmermann, P. Müller, S. Stinca and C. Lacroix, Nutr. Diabetes, 2011, 1, e12.

38 N. Larsen, F. K. Vogensen, F. W. van den Berg, D. S. Nielsen, A. S. Andreasen, B. K. Pedersen, W. A. Al-Soud, S. J. Sørensen, L. H. Hansen and M. Jakobsen, PLoS One, 2010, 5, e9085.

39 M. Ibern-Gomez, C. Andres-Lacueva, R. M. Lamuela-Raventos and A. L. Waterhouse American Journal of Enology and Viticulture, Am. J. Enol. Vitic., 2002, 53, 218-221.

40 A. I. Romero-Pérez, M. Ibern-Gomez, R. M. Lamuela-Raventos and M. C. de La Torre-Boronat, J. Agric. Food Chem., 1999, 47, 1533-1536. 
41 M. Arumugam, J. Raes, E. Pelletier, D. Le Paslier, T. Yamada, D. R. Mende, G. R. Fernandes, J. Tap, T. Bruls, J. M. Batto, M. Bertalan, N. Borruel, F. Casellas, L. Fernandez, L. Gautier, T. Hansen, M. Hattori, T. Hayashi, M. Kleerebezem, K. Kurokawa, M. Leclerc, F. Levenez, C. Manichanh, H. B. Nielsen, T. Nielsen, N. Pons, J. Poulain, J. Qin, T. Sicheritz-Ponten, S. Tims, D. Torrents, E. Ugarte, E. G. Zoetendal, J. Wang, F. Guarner, O. Pedersen, W. M. de Vos, S. Brunak, J. Dore, H. I. T. C. Meta, M. Antolin, F. Artiguenave, H. M. Blottiere, M. Almeida, C. Brechot, C. Cara, C. Chervaux, A. Cultrone, C. Delorme, G. Denariaz, R. Dervyn, K. U. Foerstner, C. Friss, M. van de Guchte, E. Guedon, F. Haimet, W. Huber, J. van Hylckama-Vlieg, A. Jamet, C. Juste, G. Kaci, J. Knol, O. Lakhdari, S. Layec, K. Le Roux, E. Maguin, A. Merieux, R. Melo Minardi, C. M'Rini, J. Muller, R. Oozeer, J. Parkhill, P. Renault, M. Rescigno, N. Sanchez, S. Sunagawa, A. Torrejon, K. Turner, G. Vandemeulebrouck, E. Varela, Y. Winogradsky, G. Zeller, J. Weissenbach, S. D. Ehrlich and P. Bork, Nature, 2011, 473, 174-180.

42 M. Boto-Ordonez, M. Urpi-Sarda, M. I. Queipo-Ortuno, S. Tulipani, F. J. Tinahones and C. Andres-Lacueva, Food Funct., 2014, 5, 1932-1938.

43 S. Vendrame, S. Guglielmetti, P. Riso, S. Arioli, D. KlimisZacas and M. Porrini, J. Agric. Food Chem., 2011, 59, 1281512820.

44 M. Hidalgo, J. Oruna-Concha, S. Kolida, G. E. Walton, S. Kallithraka, J. P. Spencer and S. de Pascual-Teresa, J. Agric. Food Chem., 2007, 60, 3882-3890.

45 D. Hervert-Hernandez, C. Pintado, R. Rotger and I. Goni, Int. J. Food Microbiol., 2009, 136, 119-122.

46 X. Tzounis, A. Rodriguez-Mateos, J. Vulevic, G. R. Gibson, C. Kwik-Uribe and J. P. Spencer, Am. J. Clin. Nutr., 2011, 93, $62-72$.

47 G. R. Gibson, E. R. Beatty, X. Wang and J. H. Cummings, Gastroenterology, 1995, 108, 975-982.

48 R. Rastmanesh, Chem. Biol. Interact., 2011, 189, 1-8.

49 R. Lopez-Sepulveda, R. Jimenez, M. Romero, M. J. Zarzuelo, M. Sanchez, M. Gomez-Guzman, F. Vargas, F. O'Valle, A. Zarzuelo, F. Perez-Vizcaino and J. Duarte, Hypertension, 2008, 51, 1088-1095.
50 P. D. Cani, A. M. Neyrinck, F. Fava, C. Knauf, R. G. Burcelin, K. M. Tuohy, G. R. Gibson and N. M. Delzenne, Diabetologia, 2007, 50, 2374-2383.

51 N. Burger-van Paassen, A. Vincent, P. J. Puiman, M. van der Sluis, J. Bouma, G. Boehm, J. B. van Goudoever, I. van Seuningen and I. B. Renes, Biochem. J., 2009, 420, 211219.

52 K. Lewis, F. Lutgendorff, V. Phan, J. D. Soderholm, P. M. Sherman and D. M. McKay, Inflammatory Bowel. Dis., 2010, 16, 1138-1148.

53 L. Y. Peng, Z. Li, R. S. Green, I. R. Holzman and J. Lin, J. Nutr., 2009, 139, 1619-1625.

54 H. V. Lin, A. Frassetto, E. J. Kowalik Jr., A. R. Nawrocki, M. M. Lu, J. R. Kosinski, J. A. Hubert, D. Szeto, X. Yao, G. Forrest and D. J. Marsh, PLoS One, 2012, 7, e35240.

55 D. M. Saulnier, S. Kolida and G. R. Gibson, Curr. Pharm. Des., 2009, 15, 1403-1414.

56 K. Tahri, J. Crociani, J. Ballongue and F. Schneider, Lett. Appl. Microbiol., 1995, 21, 149-151.

57 S. Rabot, M. Membrez, A. Bruneau, P. Gerard, T. Harach, M. Moser, F. Raymond, R. Mansourian and C. J. Chou, FASEB J., 2010, 24, 4948-4959.

58 V. R. Velagapudi, R. Hezaveh, C. S. Reigstad, P. Gopalacharyulu, L. Yetukuri, S. Islam, J. Felin, R. Perkins, J. Boren, M. Oresic and F. Backhed, J. Lipid Res., 2010, 51, 1101-1112.

59 S. P. Claus, S. L. Ellero, B. Berger, L. Krause, A. Bruttin, J. Molina, A. Paris, E. J. Want, I. de Waziers, O. Cloarec, S. E. Richards, Y. Wang, M. E. Dumas, A. Ross, S. Rezzi, S. Kochhar, P. Van Bladeren, J. C. Lindon, E. Holmes and J. K. Nicholson, mBio, 2011, 2, e00271.

60 P. D. Cani, J. Amar, M. A. Iglesias, M. Poggi, C. Knauf, D. Bastelica, A. M. Neyrinck, F. Fava, K. M. Tuohy, C. Chabo, A. Waget, E. Delmee, B. Cousin, T. Sulpice, B. Chamontin, J. Ferrieres, J. F. Tanti, G. R. Gibson, L. Casteilla, N. M. Delzenne, M. C. Alessi and R. Burcelin, Diabetes, 2007, 56, 1761-1772.

61 G. Musso, R. Gambino and M. Cassader, Diabetes Care, 2010, 33, 2277-2284.

62 N. Fei and L. Zhao, ISME J., 2013, 7, 880-884. 